\title{
STTUDIES ON MALARIA IN CEYLON. WITH SPECIAL REFERENCE TO ITS PREVENTION IN AGRICULTURAL DISTRICTS ${ }^{1}$.
}

\author{
By P. H. BAHR, M.A., M.D., D.T.M. \& H. (Cantab.), \\ M.R.C.S., L.R.C.P. \\ London School of Tropical Medicine.
}

(With Plates VIII-XIII and 2 Maps.)

For the purpose of present study, Ceylon may be regarded as presenting two definite climatic zones-the hot low plains and the damp cool tea-bearing area of the central provinces, a district lying between the isothermal lines of $70-75^{\circ} \mathrm{F}$. (vide map 1 ); these two zones are probably the main factors in influencing the distribution of malaria in the island.

Malaria is par excellence a scourge of the low-country, which may again be divided for our present purpose into the hot damp agricultural districts of the Western and Southern, and the hot but dry jungles of the North and Eastern Provinces.

I have been unable in Ceylon, in contradistinction to what we know of the endemic malaria of the Malay States and of the Himalayas, to obtain any evidence of fresh infections arising at an elevation above $2200 \mathrm{ft}$., though it is said that epidemics have occurred in former times at an elevation considerably higher than this in certain narrow and confined valleys near Kandy. In the Tamil coolies employed on the tea plantations, relapses of an infection acquired originally in India or in Ceylon at a lower elevation may occur, especially during the southeast Monsoon, but malaria per se cannot be regarded as affecting in any way the salubrity of the upcountry tea estates. It is otherwise on the rubber plantations of the Western Province and in the rice

1 Based on information collected whilst investigating sprue for the Ceylon Government. 1912-1913. 
growing and cocoanut bearing districts scattered throughout the low country.

In the jungles of the North-Central and Eastern Provinces malaria has been held responsible for the present depopulation of certain districts and the abandonment of the great cities of Anurhadhapura and Polonnurrua, formerly the seats of the ancient Sinhalese kings, and where in former times hundreds of gigantic tanks, since fallen into disrepair, were constructed, and water for the irrigation of the rice fields stored. Latterly many of these have been restored by the Government, but so far, however, probably on account of the prevalence of the endemic malaria, it has been found difficult to induce any natives to take up the cultivation of the adjacent rice-fields.

I have studied malaria in detail in three areas in Ceylon, namely, Kurunegala in the North-Western, Badulla in Uva, and Tangalla in the Southern Provinces. On the west coast it has been studied in detail by Major S. P. James at Talaimannar, the Ceylon terminus of the new railway to India.

The variety of malaria parasite found.

Blood films were taken from 539 natives, a quarter of an hour being allotted to the examination of each slide. The parasite rate was found to be $14.4 \%$; in the majority of cases the infection of malaria parasites was a small one, only a single gamete or ring-form being found in the whole film.

The quartan parasite greatly predominated and formed $63.8 \%$, the benign tertian $19.2 \%$, and the subtertian $17 \%$, of the total number examined. Double infections were found only five times as follows :

Tertian and quartan twice.

Quartan and subtertian once.

Tertian and subtertian once.

Quartan, tertian and subtertian once.

Crescents, or gametocytes, were found eight times out of fourteen subtertian infections, an abnormally high proportion when contrasted with the small number found by Plehn and others in this infection in Africa. A similar preponderance of the quartan parasite was found by Christophers (Sci. Mem. Govt. India, 1912, New Series, No. 56) in his recent work in the Andamans, a fact he wishes to attribute to the proneness of the infection to relapse and to the relatively small number of gametocytes produced by the quartan, as compared with other forms of the malaria parasite. 


\section{The Ceylon anopheline mosquitoes.}

The following is a list of anopheline mosquitoes I collected in Ceylon, identified by Col. Alcock, C.I.E., F.R.S., and Major S. P. James, I.M.S.

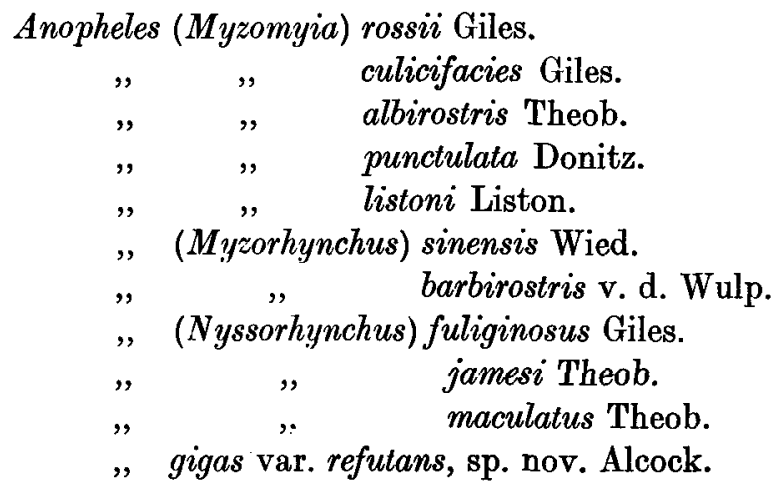

(Refutans is similar to gigas except for three or four very narrow light tawny bands on the palps one of which is situated at the tip.)

of these no less than six species have been recognized as malaria carriers in other parts of the tropics, but so far only one, M. culicifacies, has definitely been proved-by Major James in Talaimannar-to be the natural carrier of infection in Ceylon.

Anopheles gigas var. refutans was only found breeding at an elevation of $6000 \mathrm{ft}$; ; even in Nuwara Eliya it was a scarce species, and hardly ever entered the houses or showed any proclivity to feed on human blood. Only two other species of Anopheles, M. rossii and N. maculatus, were found breeding in the swift streams at that altitude; the latter species, although a recognized carrier in Malaya, appears to play little part in the spread of malaria in Ceylon; it is possible that the temperature encountered in its breeding areas is too low to permit of the complete developmental cycle of the parasite in this definitive host to take place.

M. culicifacies is generally conceded by Christophers and James to be the main natural malaria-carrier in India, and has also been found naturally infected by the latter in Ceylon.

$M$. albirostris has been found naturally infected with zygotes both in India and the Malay States.

$M$. listoni has been found naturally infected in India and is capable of transmitting malaria in captivity.

M. sinensis is recognized as a carrier of the benign tertian parasite by Tzuzuki in Japan, and has been found infected with zygotes by Stanton on two occasions. 
M. fuliginosus has been found naturally infected in India by J. R. Adie, and in Malaya by Stanton.

$N$. maculatus has been found infected in nature in Malaya by Malcolm Watson, and under experimental conditions by Stanton. The former has associated its presence with severe malaria in the hill country.

Attempts were made in Kurunegala to transmit the quartan parasite through Myzorhynchus barbirostris, by far the most abundant species of anopheline, without success. Great difficulty was experienced in finding a suitable case of infection and in inducing the native to submit to mosquito bites at night time.

\section{Malaria in Kurunegala.}

Malaria was studied in greatest detail in Kurunegala. This town, 381 feet above sea-level, is the capital of the North-Western Province, and the centre of an important agricultural district mainly devoted to the cultivation of cocoanuts ; it is also an important labour distributing centre to districts which have been considerably opened up during the last 20 years. It is situated 58 miles by rail from Colombo and is the residential centre of the local staff of the Northern line.

According to the 1911 census there is within the limits of the town, which occupies an area of over four square miles, a population of 8100 .

Within these limits also there are over 500 acres of paddy or rice fields, but only 300 of these are of importance for our present purpose, as the remainder are cut off by a series of bare rocks (vide Map 2) which arise abruptly towards the north-east of the town, and may on that account be disregarded as having any influence on the spread of the malaria in the town proper.

The town consists of a number of residential houses and a bazaar of about 15 acres in extent occupied by ill-kept straggling boutiques or small shops. The houses of the better classes are scattered along the main roads and converge on the bazaar.

Towards the north of the town there is a tank of some ten acres in extent which is used for irrigation purposes and to a limited extent for bathing and drinking. A water course emerging from this supplies the adjacent paddy fields and eventually joins a stream called the Boo Ela; this latter has its source in another large tank named the "Wenaruwewa" situated a mile beyond the southern town limits.

The inhabitants of Kurunegala can be divided into four social classes, (1) the Government servants employed in the Government offices and 
P. H. BAHR

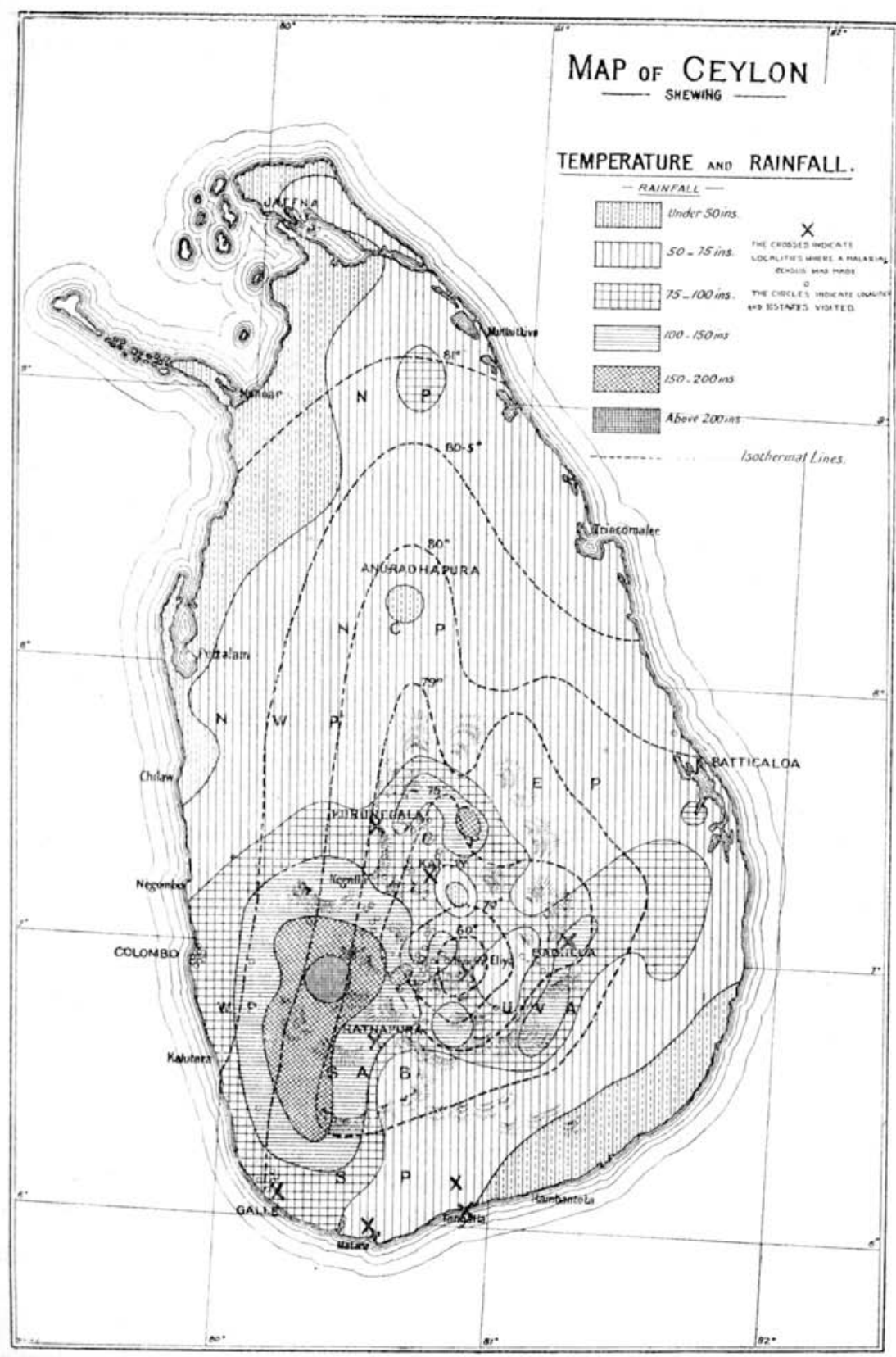

Map 1. 
on the railway, (2) the boutique or small shop keepers, (3) villagers or "goiyas," perennially engaged in tilling and irrigating the rice fields, and (4) colonies of Tamil oilmongers engaged in extracting cocoanut oil from copra.

\section{Climate.}

The annual rainfall is 80.5 inches, the wettest months are April, May, October and November; the average mean temperature is $78.8^{\circ} \mathrm{F}$. about equal to that of Colombo.

\section{Malaria in Kurunegala.}

I am much indebted to Dr S. T. Gunasekara, who has been resident for one and a half years in the town, and who has made a most extensive study of the subject, for many facts regarding the epidemiology and incidence of this disease, and which he has incorporated in a report recently issued (Ceylon, 1913, xxxvII).

The town of Kurunegala (pronounced Cornygalle) has always borne a bad reputation for malaria, as witnessed by the term "Kurunegala fever " by which malaria is popularly known throughout Ceylon. From time to time it has assumed epidemic proportions in the town and has been a source of serious loss to the Government and to the planting industry. According to the records compiled by Gunasekara the epidemics have generally occurred after a season of moderate rainfall followed by prolonged drought; such a drought is apt to favour the propagation of malaria, firstly by drying up all the natural pools in the town and thereby killing off the larvivorous fish, thus affording suitable breeding places for anophelines after the rains where they can breed undisturbed, and secondly by the hardships which such a drought entails and which predispose the poorer natives to relapses of a previous infection.

There are as a rule two malaria seasons in Kurunegala every twelve months, each following the Monsoon rains. For the eight years, 19041911, Gunasekara has constructed a chart showing the incidence of malaria in the district, and from which he has been able to arrive at several important conclusions as regards the epidemiology of the disease in the Kurunegala district.

The main points are as follows:

(1) In the years 1906, 1908 and 1911 malaria assumed epidemic proportions. 
(2) The fastigia of temperature and of rainfall generally coincide; the curve of malaria incidence commences to rise after the fastigium of climatic influences and reaches its maximum in three or four months.

(3) There are generally two rises in the malaria incidence during the year; of which the one occurring during August, September, and October is generally the highest.

\section{Mortality from malaria.}

The average annual death-rate from malaria is about 109 per annum, or $1.3 \%$, but in 1911 it rose to 175 per annum, or $2.1 \%$. Not only has malaria been directly responsible for this large number of deaths, but it has also been the source of serious inefficiency and direct loss to the Government in other ways. From the statistics Gunasekara compiled it appears that normally considerably over $22 \%$ of the Government officers in Kurunegala are annually incapacitated from service on account of fever.

\section{Anti-malarial measures so far adopted in Kurunegala.}

The anti-malarial measures instituted under the guidance of $\mathrm{Dr}$ Gunasekara have been designed to improve the general sanitation of the town and to prepare the masses for a still more extensive campaign. These have consisted in, $(a)$ education of the public in malarial prophylaxis by means of lectures, $(b)$ general sanitary measures, $(c)$ daily quinine distribution, $(d)$ mosquito reduction by gangs of coolies clearing drains, filling in hollows, etc., $(e)$ screening hospital wards, Government bungalows, etc.

Though all these measures have been conscientiously carried out for the last one and a half years, it was realised that the amount of malaria had not been apparently reduced. For political and economic reasons no steps had been taken to abolish the paddy fields in the centre of the town as it had been deemed advisable to observe the part these fields played in the spread of the malaria.

At the request of the Hon. the Colonial Secretary of Ceylon, I spent a week in February and March, 1913, in Kurunegala studying this question; the main results of this enquiry are embodied in the present report.

435 blood slides were taken and microscopically examined. I wish to express my indebtedness to Sir Patrick Manson for the interest he has taken in the progress of the work, and for his invaluable assistance in the tedious task of examining the blood slides. 
I have also received considerable assistance from Major S. P. James. He has confirmed, and in many cases corrected, my diagnosis of the local anopheline mosquitoes.

In considering this report it must be borne in mind that the weather was abnormally dry at the time of my visit, consequently the paddy fields lay fallow; there were very few mosquitoes and little, if any, actual fever. The results, however, may be considered of some scientific value as indicating the condition of affairs when the town is free from epidemic malaria.

I wish to express to Dr S. P. Gunasekara my gratitude for the assistance he has afforded me in this enquiry.

The local anopheline mosquitoes.

The main species of anopheline mosquitoes found by me in Kurunegala, in order of their frequency, are as follows :

(1) Myzorhynchus barbirostris.

(2) Myzomyia rossii.

(3) Myzorhynchus sinensis.

(4) Myzomyia culicifacies.

(5) Myzorhynchus fuliginosus.

(6) Myzorhynchus jamesi.

(7) Myzomyia punctulata, an uncommon species in Kurunegala.

(8) Myzomyia albirostris, only three or four specimens were bred from larvae collected in the paddy fields.

(9) Nyssorhynchus maculatus, a rare species in Kurunegala, bred from larvae obtained in a swift-flowing stream behind the Government Agent's house.

(10) Myzomyia listoni, only one specimen obtained.

Thus, out of ten species of Anopheles found in Kurunegala, six have been proved elsewhere, mostly in Malaya and in India, to be conveyers of malaria. Of the known malaria carriers, Myzomyia culicifacies was by far the most abundant species.

Adult anopheline mosquitoes have been found in houses in Kurunegala and in various bungalows in the town during the daytime by Gunasekara. They were mostly specimens of $M$. barbirostris and $M$. sinensis. The railway station bungalows, where malaria is so prevalent, have often been searched by Gunasekara, without result. 
PARASITOLOGY, VOL. VII. NO. 2

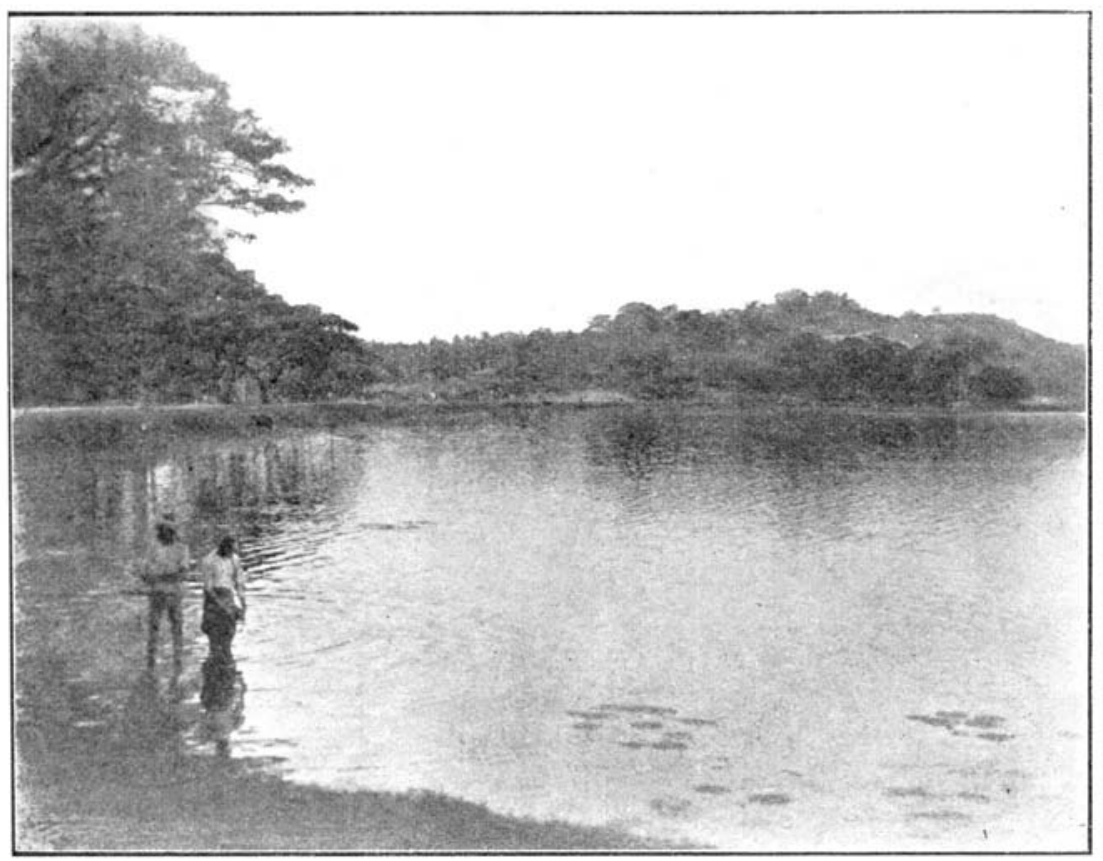

Fig. 1. Kurunegala Tank. Numerous larvivorous fish, but no anopheline larvae.

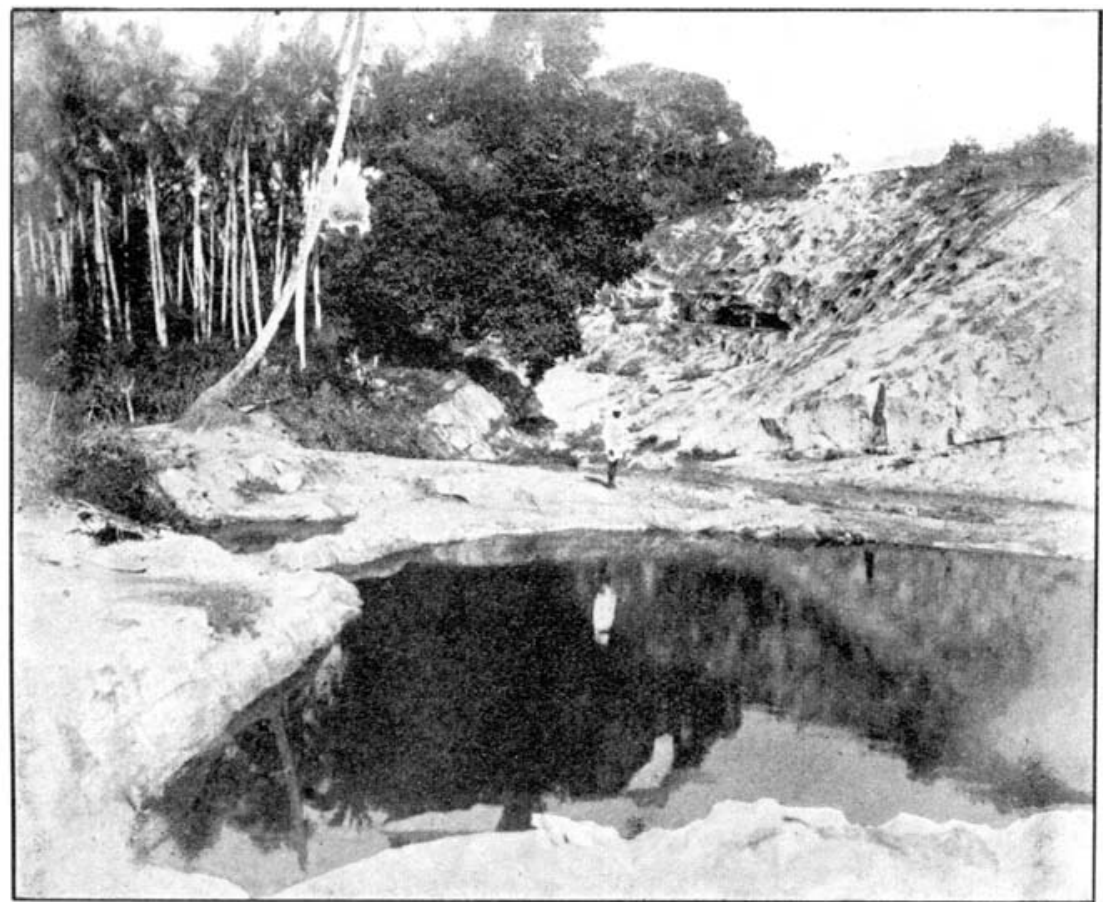

Fig. 2. Rock Pool. A rainwater pool in the Quarry. Breeding place of M. barbirostris, M. sinensis, and $M$. rossii. 
This he attributes to the amount of uncleared jungle in the vicinity, into which the anophelines retire during the daytime. I failed to find any anophelines in the houses of Habage village (Appendix II A) during an extensive search in the daytime.

The areas in which these anophelines breed.

For this purpose we have to consider the main sheets of water found in Kurunegala town. I propose to say a few words about each area in turn.

(1) Paddy Fields; within the town limits these extend over an area of about 300 acres. The majority of these fields act as breeding grounds of mosquitoes only at certain seasons of the year when they are flooded, and more especially, according to Gunasekara's observations, when the water is subsiding and leaving small isolated pools behind. Certain fields supplied by the town wells and by the irrigation channel from Wenaruwewa tank (vide Pl. X, fig. 5) are, however, nearly always more or less under water. Bylreference to the map it will be seen that the paddy fields in the town are supplied with water from two main sources. The block on the Negombo road is supplied from the Kurunegala tank by an irrigation channel eventually joining the Boo Ela; the other two blocks, one on the Colombo road, the other near the railway station, are supplied by an irrigation channel from the Wenaruwewa tank, situated one mile without the town limits. Water is supplied from this tank twice weekly, or whenever possible, mainly for filling the locomotive sump at the railway station, with which it is connected.

According to Gunasekara's observations these permanently flooded fields act as a constant breeding ground of anophelines all the year round.

(2) Tanks. There are two tanks to be considered, the main tank and a bathing tank (vide Pl. $\mathrm{X}$, fig. 4), on the Puttalam road; both are stocked with fish. No larvae have ever been found in either, so they may be dismissed as factors in the situation.

(3) Irrigation Channels. When properly graded and when the water is flowing fast, little danger is to be expected from this source. The natives, however, are in the habit of partially damming up these channels in order to catch fish, thus creating stagnant pools, in which anophelines breed. This practice should be forbidden. The side channels leading off from the main channels are also a source of danger. These are so graded that the water has gradually to well up from below in 
order to fill them, and thus cannot flow by force of gravity alone. On subsiding, the water leaves stagnant pools behind, in which larvae are to be found. This is especially so in the case of the channel situated behind the station (vide Pl. XI, fig. 7).

(4) Rock Pool (Pl. VIII, fig. 2). This is a rainwater pool, which has collected in a disused quarry. Great numbers of larvae can nearly always be found there, though their numbers have been somewhat lessened by the introduction of fish by Gunasekara.

(5) Borrow Pits (PI. XIII, fig. 11). Many of these have been excavated by the Public Works Department during their work on the Circular Road in the south of the town; formerly they used to be fertile breeding grounds of anophelines. The majority have been dealt with under Gunasekara's directions; as a focus of malarial infection they may now be almost disregarded.

(6) Freshwater Wells. According to Gunasekara there are 180 town wells; in only 18 of these were a few larvae found. Larvivorous fish have now been introduced, so that as centres of infection they, too, may be disregarded. One well supplies some blocks of paddy fields on the Rajaphilla road; these are nearly always under water, and larvae can always be found there (Pl. X, fig. 5).

(7) Rock Stream (Pl. IX, fig. 3). This stream flows behind the Government Agent's residence; in the dry season it is represented by a series of stagnant pools. From larvae captured there, M. barbirostris and one specimen of $M$. maculatus (vel wilmori) have been bred. Reference must here be made to a practice of the villagers of damming up this stream to form a bath for their bulls, thys creating large stagnant pools; this practice also ought to be forbidden.

(8) Water Channels on each side of Railway Cutting (Pl. XII, fig. 8). This water supplies the engines at the station. The courses are only cemented underneath the bridge, and are not kept clean; the result is that they are overgrown with slimy water plants (spirogyra), which form an excellent feeding ground for larvae, and to which they adhere by their tails. This stream, and the presence of continually flooded paddy fields in the vicinity, probably account for much of the malaria amongst the railway staff for which the station at Kurunegala has an invidious reputation. There is no reason why this reproach to the Railway Department should not be removed, and increased efficiency result. The following list will give an idea of the importance of these various sheets of water in breeding malaria-conveying anophelines. Malaria carriers are printed in heavy type: 


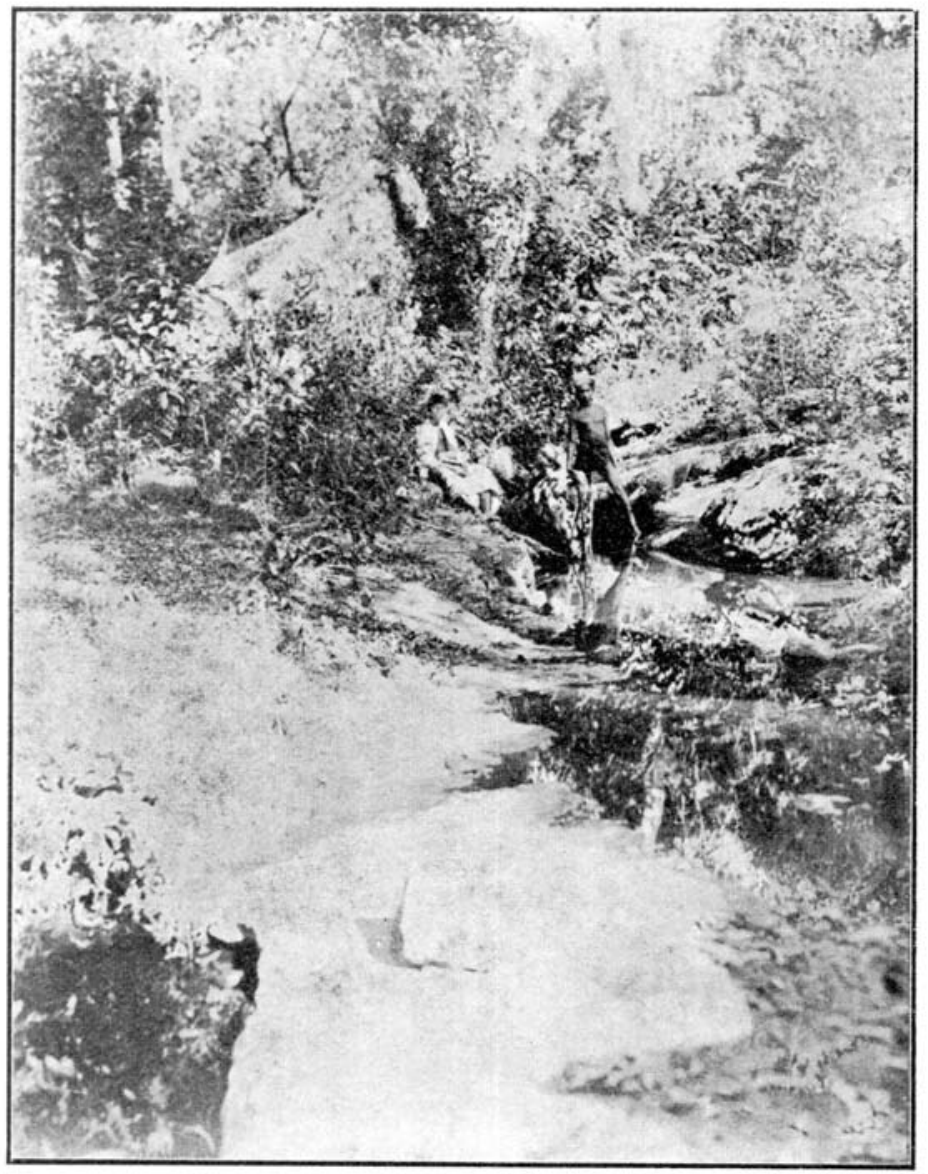

Fig. 3. Rock Stream. A swift stream flowing behind the Government Agent's residence. Breeding place of $M$. barbirostris, $M$. rossii, and $M$. maculatus, showing method of blocking stream to wash cattle. 


\begin{tabular}{|c|c|c|c|c|}
\hline & \multicolumn{4}{|c|}{ Nature of Breeding Ground } \\
\hline & & $\begin{array}{l}\text { Paddy } \\
\text { Fields }\end{array}$ & $\begin{array}{l}\text { Rock } \\
\text { Pool }\end{array}$ & $\begin{array}{l}\text { Railway } \\
\text { Cutting }\end{array}$ \\
\hline M. barbirostris & .. & 19 & 47 & - \\
\hline M. rassii $\quad$.. & .. & 26 & 42 & 14 \\
\hline M. sinensis $\ldots$ & .. & 15 & 7 & - \\
\hline M. culicifacies & .. & $\mathbf{3}$ & - & 7 \\
\hline M. fuliginosus & .. & 1 & - & - \\
\hline M. jamesi .. & .. & 2 & $\ldots$ & - \\
\hline M. punctulata & .. & l. & - & - \\
\hline Total exam & & 67 & 96 & 21 \\
\hline
\end{tabular}

The water from these various areas containing larvae was placed in separate cages, as has already been related. Each mosquito hatched was identified.

From this table it will be readily gathered that a greater variety and higher proportion of malaria-conveying anophelines have been bred from paddy fields than from elsewhere. In this connection I must consider shortly the natural enemies of the mosquito larvae in the paddy fields. These are :

(1) Larvivorous fish; of these four varieties are found, three of which are surface feeders, as follows:

(a) "Pathia" (Barbus stigma), a most efficient larvivore;

(b) "Dandie" (Rasbora lanicornius);

(c) "Sudaya" (Danio malabaricus);

(d) "Ahirawa" (Lepidociphalicthys thermalis), a bottom feeding fish.

These species are found in all paddy fields when in flood. In the first instance, they escape from the tanks and are carried to the fields by the irrigation channels; it is thought, however, that a certain number are carried to remote blocks as spawn on the feet of water birds. As far as is known, they all multiply in the paddy fields, provided that there is sufficient water. Gunasekara has made numerous observations on their larvivorous propensities. It appears that these species will only feed on live larvae. Many of the anopheline larvae have in consequence adopted the habit of shamming death, and many doubtlessly escape by this means. It is a fallacy to think, however, that whenever these fish are found in paddy fields no larvae can be found at the same time. This is not so. There are several explanations of this fact:

(a) Larvae are generally found in the "seepage" water which has filtered through the bunds, leaving the fish behind.

(b) In the larger pools which form in the paddy fields the larvae are found at the edges of the pools, while the fish keep the centre. 
(c) Holes formed by the feet of cattle (vide Pl. XI, fig. 6), and into which the fish are not able to enter, are ideal breeding places, and in these Anopheline larvae are invariably found.

Frogs abound in all streams and paddy fields, but they do not appear to feed on larvae at all.

(2) Larvivorous larvae. The commonest larvae with cannibalistic proclivities are the large Culicine larvae of Culex concolor, a common and voracious mosquito often found in the roofs of native houses. These larvae are frequently met with in paddy field water.

The effect of these areas on the prevalence of local malaria.

Adopting the plan which has been utilized, whenever malaria has been adequately studied, I have taken the degree of infection of children under fourteen years of age as an index of the general population.

To determine which of the breeding grounds is the main focus of infection, two courses are open--one, to determine the evidences of past; the other, of present malarial infection-

(1) By taking the splenic index.

(2) By microscopical examination of the blood.

(1) Splenic Index of the Children. 435 children have been examined by abdominal palpation to determine the percentage with enlarged spleens (Appendix I). These children have been selected in batches, bred and born in certain areas of the town. As far as was possible every child in Kurunegala was examined. The total spleen rate was found to be $34 \cdot 7$ per cent., and was higher in males than in females. In the male sex the highest index was found to be reached by the tenth, in the female by the twelfth year (Appendix I).

A cursory glance at the map will convince the reader that the incidence of malaria, as judged by the spleen rate, varies considerably in various parts of the town; detailed statistics on this point are given in Appendix II. The letters A, B, C, etc. on Map 2 refer to different collections of houses where these observations were made.

The conclusions I arrived at from this study are that, wherever the houses are crowded together in the vicinity of paddy fields, there the spleen rate is a high one, irrespective of the social status of the inhabitants or of the sanitary conditions under which they are living. There are one or two areas to which I would call attention. 
PARASITOLOGY, VOL. VII. NO. 2

PLATE $X$

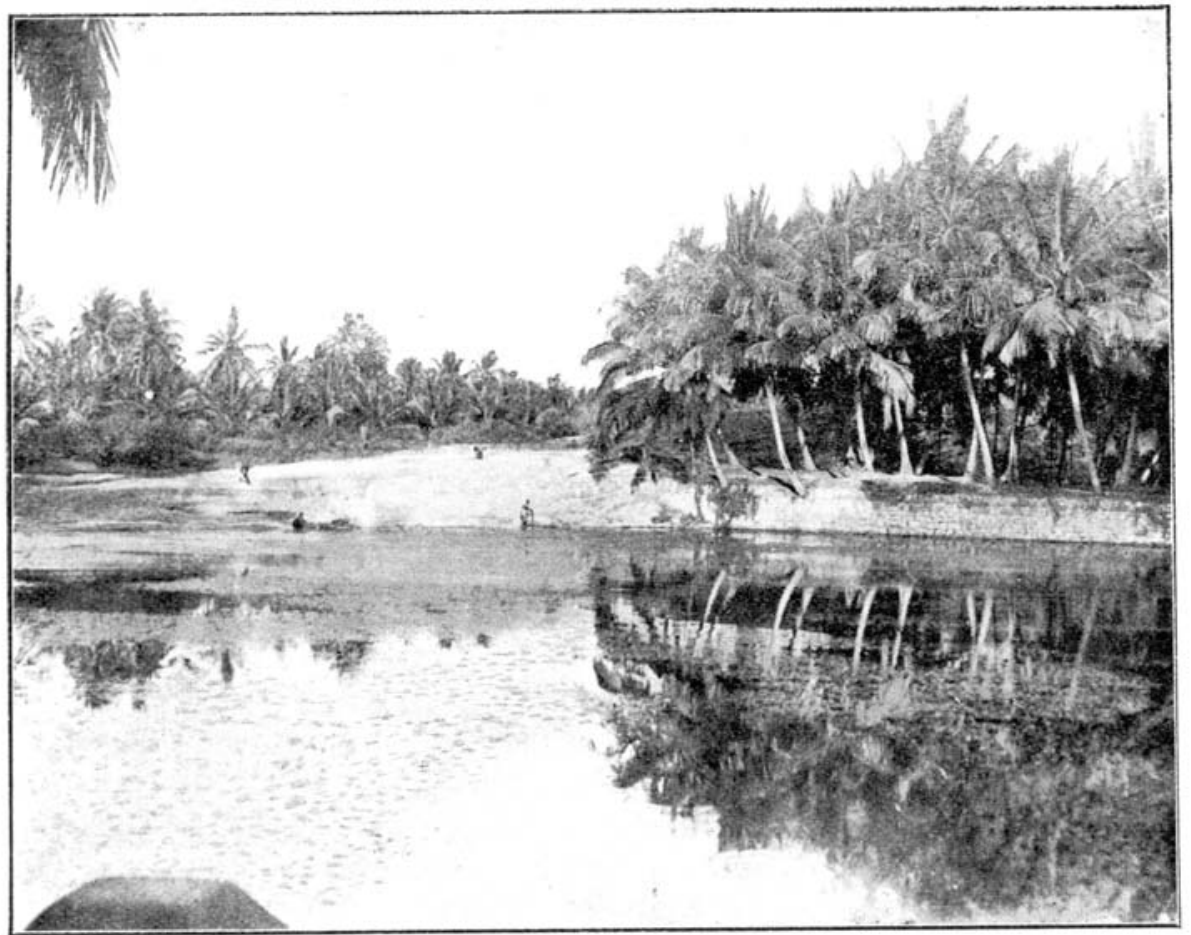

Fig. 4. Bathing Tank. Tamil Oilmongers' quarters, Puttalam Road. Numerous larvivorous fish. No anopheline larvae.

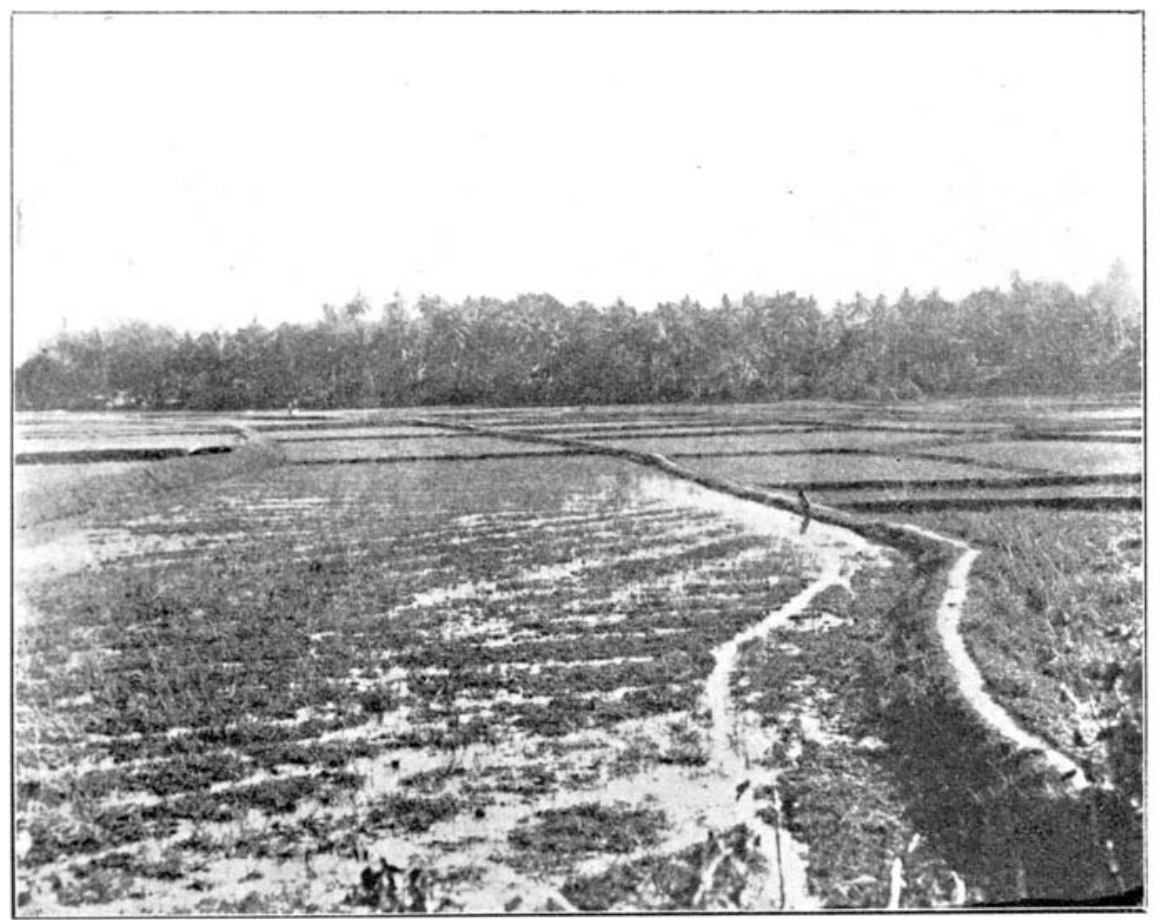

Fig. 5. Permanently Flooded Paddy Fields. (On the Rajaphilla Road.) These fields are supplied by well water and constitute a permanent breeding ground of anophelines. 
In the area marked $H$, although the children are of a good social status, well fed, and well eared for, the spleen rate is high $-68^{\circ} 1$ per cent. These houses are built upon the Bund of a paddy field (Pl. XII, fig. 9).

$A$ and $K$ are similarly situated areas, the inhabitants are of the same class (" goiyas "), but the houses are scattered, and consequently there is less chance of the conveyance of infection; the spleen rate is here a lower one.

The absence of any evidences of malaria at $\mathrm{C}$ is easily explicable. A small number of children only could be examined; these had but recently, being the families of the police, arrived in the district.

The areas marked $\mathrm{F}$ and $\mathrm{G}$ respectively next call for a few comments. $\mathrm{G}$ is a village inhabited by Sinhalese "goiyas," in close proximity to paddy fields, which, being naturally marshy ground, are nearly always flooded. The spleen rate, 83.3 per cent., is the highest encountered in Kurunegala, yet this village is separated only by a small belt of cocoanut and areca palms from the miserable and insanitary quarters of the Tamil oilmongers (F, Pl. XIII, fig. 10); these latter quarters adjoin a bathing tank (Pl. X, fig. 4), which, on account of the number of fish which inhabit it, does not serve as a breeding area of anophelines.

At $F$ the splenic index is less than half of that at $G$. The explanation of this fact would appear to be that the belt of trees I have already mentioned serves to screen off to some extent the mosquitoes bred in the paddy fields at G. It must be conceded that there is a great disparity between the prevalence of malaria amongst the children bred in the vicinity of these paddy fields and amongst the ill-kept denizens of the bazaar (L), where the spleen rate is but $7 \cdot 1$ per cent. These facts, together with those already related, are to my mind sufficient to condemn the paddy fields as constituting the main foci of malarial infection in Kurunegala.

(2) Microscopic Examination of the Blood. The blood of all these 435 children was systematically examined. The result will be found detailed in Appendix III. Malaria parasites were only found 45 times. The mean parasite rate for the whole town works out at 10.5 per cent. The rate varies in different areas; it is to be noted that at $H$, where the spleen rate is highest, the parasite rate is low. There are various factors to account for this apparent anomaly. The parasites, in all but two instances, were present in very scanty numbers : often but one parasite could be found in a slide, and it is therefore probable that many small infections were overlooked. None of the children were suffering from fever at the time of examination, the infection in nearly every 
instance being at a quiescent stage, ready to break out when conditions again became favourable. The gametocyte cell was the one most frequently encountered.

The quartan parasite (Appendix III) predominated, an experience which tallies with the recent work of Major Christophers, I.M.S., in the Andamans.

Malignant or sub-tertian crescents were only found three times. All three species of malaria parasite - the quartan, tertian, and subtertian-were represented. It is of great interest to note that malaria parasites were found in the blood of 15 children, in whom no concomitant enlargement of the spleen could be detected.

Results of systematic treatment with Quinine. Special enquiries were made during this investigation with regard to the effect of regular treatment with quinine. On the whole, the children impressed me as being a remarkably healthy set, well-fed, mentally alert, with sleek and glossy skins, presenting in this respect a contrast to the anaemic, ill-kept, rough-skinned village children met with in malarious districts in the Southern Province.

It was found that a very small proportion of the children had been regularly treated with quinine-only 43 out of the total number examined had been so treated; the spleen rate amongst those treated was 60.4 per cent., and the parasite rate 13.9 per cent., as against a spleen rate of 33.8 per cent. and a parasite rate of 9.9 per cent. amongst those who had had no treatment at all. It must be understood that these figures do not represent the real efficacy of quinine treatment; only the cachectic, anaemic children attend the Town Hall for systematic quinine administration, and it is just amongst these that a higher spleen rate is to be expected. Indeed, a considerable improvement in the spleen rate has been effected by systematic treatment, as I understand that on commencing treatment every one of these children had enlarged spleens.

The greatest difficulty with which Gunasekara has to contend is to convince the parents of the children of the necessity for systematic treatment after the one attack of fever has ended. The schools are obviously the places where systematic daily administration of quinine pills should be undertaken. In winning over the teachers to his views, Gunasekara, by the exhibition of much tact, has been particularly successful. I understand that this difficulty is greatly magnified, in so far that only 50 per cent. of the children of Kurunegala town regularly attend school. 
PARASITOLOGY, VOL. VII. NO. 2

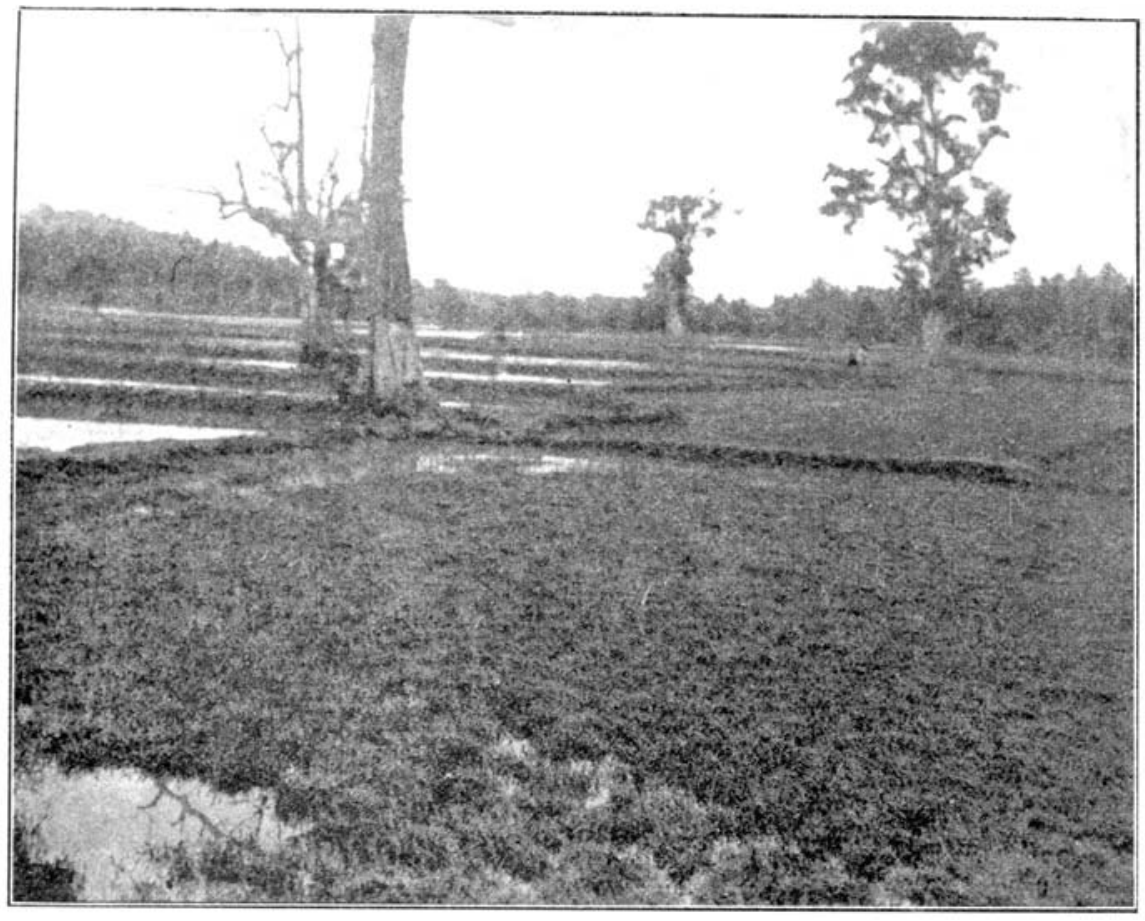

Fig. 6. Flooded Paddy Fields. (Opposite the Railway Station.) Water supplied from Wenaruwewa tank. This picture shows in the foreground pools formed by the hoof marks of cattle, in which anophelines breed.

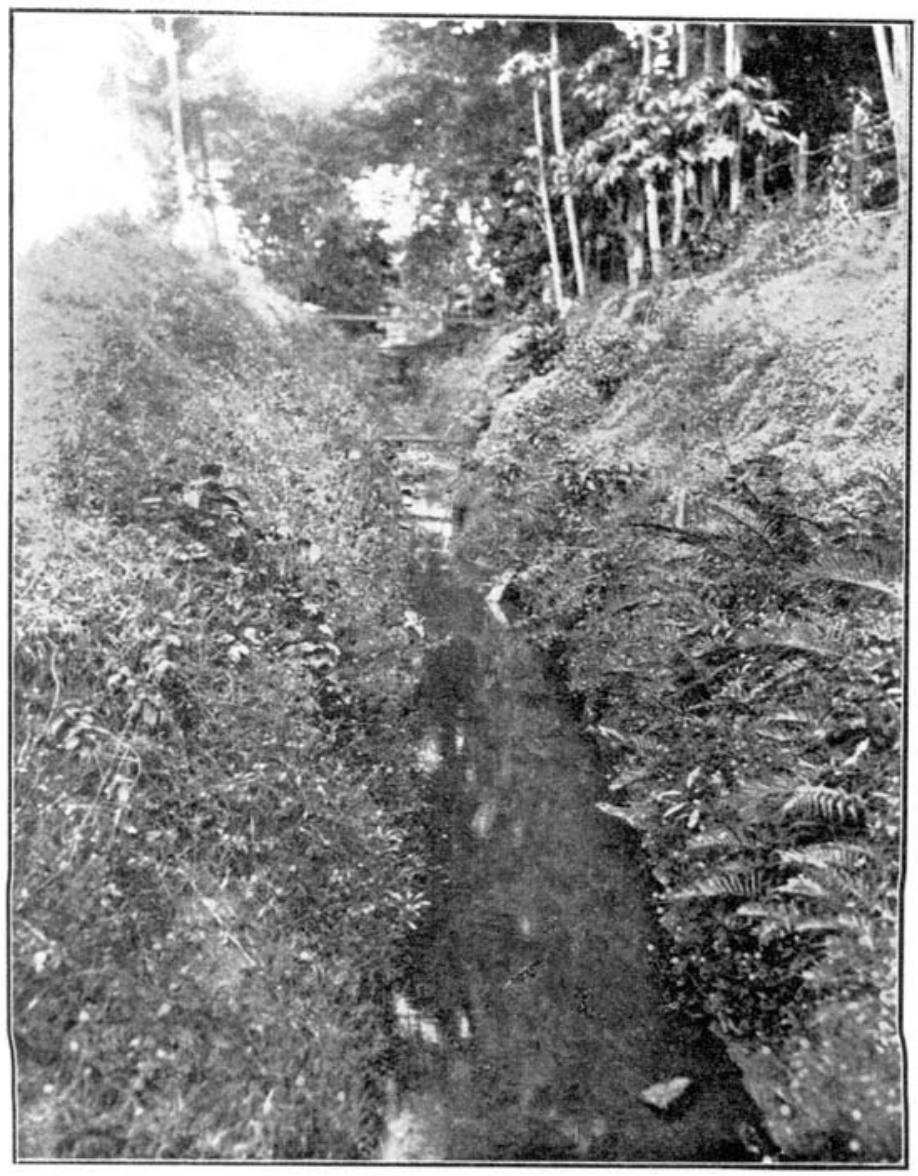

Fig. 7. Irrigation Channel. (Behind the Railway Station.) Water supplied from Wenaruwewa tank; stocked with fish. When water subsides stagnant pools are left behind, in these anophelines breed. 


\section{Conclustons.}

(1) The malaria in Kurunegala is mostly of the quartan type.

(2) That at least six well-known malaria-conveying Anophelines occur in Kurunegala.

(3) That the paddy fields are the main and most extensive breeding areas of these mosquitoes.

(4) That wet cultivation within town limits should be forbidden, as being the only means calculated to abolish endemic malaria. That this measure presents no insuperable difficulties may be seen from the perusal of figures given in Appendix V, where it is definitely stated that the substitution of cocoanut for paddy cultivation is perfectly feasible, and is indeed commercially a profitable venture.

\section{RECOMMENDATIONS.}

I venture to put forward the following recommendations based on the facts already related :

(1) Abolition of paddy fields within town limits.

(2) Systematic treatment of all school children with quinine during their attendance at school. This practice to be continued for two years after the abolition of paddy fields. Enforcement of the Town Schools Ordinance of $1908^{1}$.

(3) Cementing all drains and waterways in the town, and more especially the streams in the railway cutting. These drains, after being cemented, must be systematically cleansed of all vegetable growth.

(4) Stringent rules to prevent natives from blocking up streams and irrigation channels for the purposes of washing cattle or of catching fish.

(5) Bund of channel from Wenaruwewa tank which supplies engine sump and paddy fields near station to be kept in repair to prevent leakage.

(6) All irrigation channels should be properly graded so as to serve as outlets for storm water. In this respect the irrigation channel behind the station yard requires attention.

(7) No borrow pits to be excavated within town limits without permission of the Local Board, who alone ought to be responsible for this work.

1 An Act to enforce regular school attendance. 
(8) Rules to enforce adequate disposal of recently opened and discarded cocoanuts for drinking purposes. Owing to the abundance of firewood in Kurunegala, these shells are not used for fuel as elsewhere. In the spacious hollow water collects and forms an ideal breeding ground for all species of mosquitoes.

(9) Enforcement of a "Cattle Straying Ordinance." Could cattle be prevented from straying into paddy fields, the "goiyas "would then be able to reside at a greater distance from their work. At present, although realizing in some instances that these situations are unhealthy, they are unable to move further away on account of the damage to their crops arising from stray cattle.

\section{APPENDIX I.}

\section{Statistics.}

435 children examined, mostly between the ages of one and 12 years (there were a few of 14 and one of 16 years of age). 239 of these were males and 196 females.

Total spleen rate $34 \cdot 7$ per cent.; parasite rate 10.5 per cent.

Fifteen children were found with malaria parasites in their blood, who had no enlargement of the spleen.

(a) Spleen rate according to sex:-Males spleen rate 37.6 per cent.; females spleen rate 29 per cent.

(b) Spleen rate according to age:

\begin{tabular}{ccccccc} 
& \multicolumn{3}{c}{ MaLEs. } & \multicolumn{3}{c}{ FEMaLEs. } \\
Age & $\begin{array}{c}\text { Number } \\
\text { examined }\end{array}$ & $\begin{array}{c}\text { Number with } \\
\text { enlarged spleens }\end{array}$ & Age & $\begin{array}{c}\text { Number } \\
\text { examined }\end{array}$ & $\begin{array}{c}\text { Number with } \\
\text { enlarged spleens }\end{array}$ \\
$11-12$ & 38 & 16 or $42 \cdot 1$ per cent. & $11-12$ & 9 & 5 or $55 \cdot 5$ per cent. \\
$9-10$ & 55 & 29 or $52 \cdot 7$ per cent. & $9-10$ & 37 & 11 or $29 \cdot 7$ per cent. \\
$7-8$ & 41 & 21 or $51 \cdot 2$ per cent. & $7-8$ & 49 & 15 or $30 \cdot 7$ per cent. \\
$5-6$ & 27 & 9 or $33 \cdot 3$ per cent. & $5-6$ & 38 & 14 or $36 \cdot 8$ per cent. \\
$3-4$ & 45 & 7 or $15 \cdot 5$ per cent. & $3-4$ & 45 & 12 or $26 \cdot 6$ per cent. \\
$1-2$ & 33 & 8 or $24 \cdot 2$ per cent. & $1-2$ & 18 & - \\
\hline & 239 & 90 or $37 \cdot 6$ per cent. & & 196 & 57 or 29 per cent.
\end{tabular}

\section{ApPendix II.}

NoTE.-Explanatory details with special reference to various villages and collections of houses in Kurunegala, where detailed investigations on the prevalence of malaria were made. Alphabetical latters are employed in designating these areas, and refer to similar letters on the map. For convenience sake the inhabitants of Kurunegala town may be divided into four classes: (1) Government servants; (2) boutique-keepers ; (3) villagers or "goiyas" ; (4) Tamil oilmongers. 


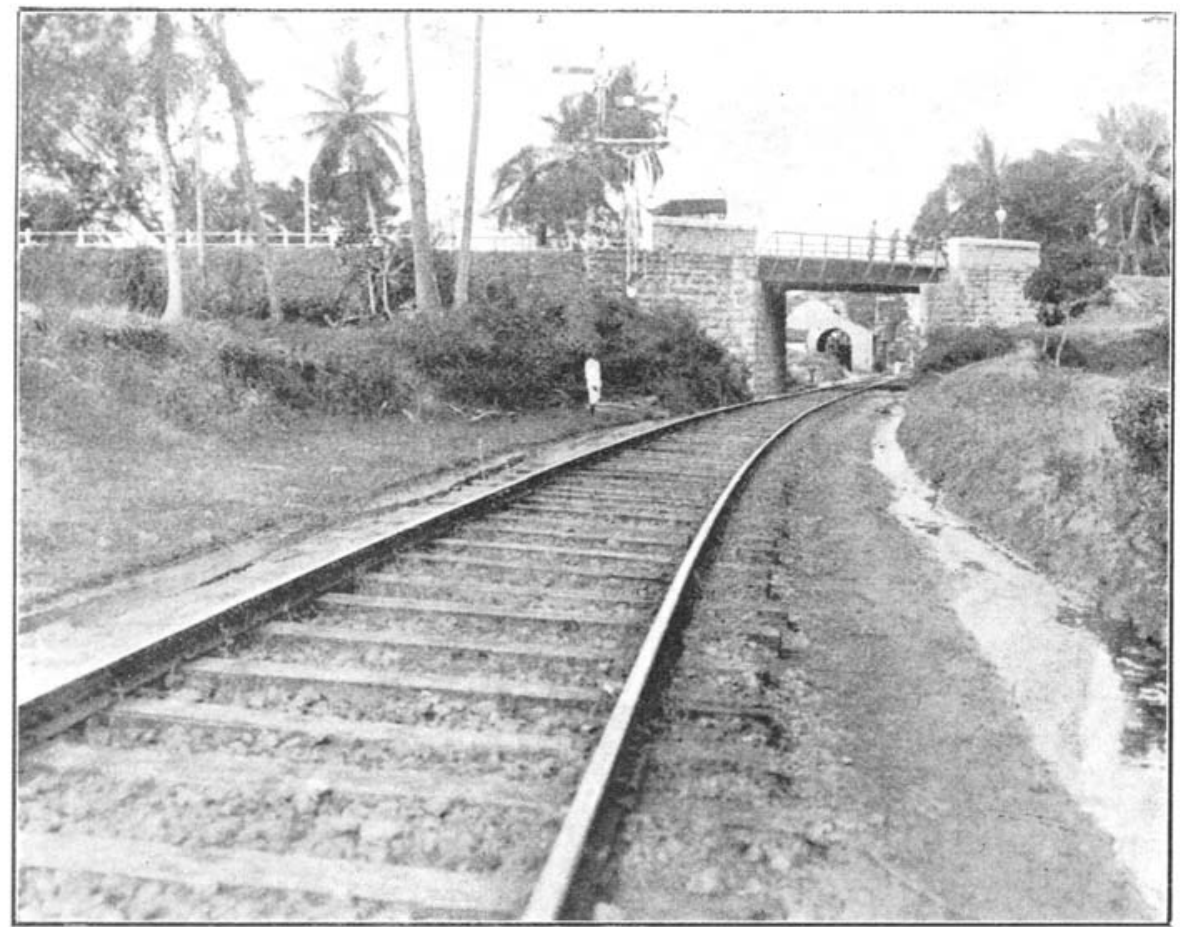

Fig. 8. Railway Cutting. Water-course flowing on each side of the permanent way and supplying locomotives with water. These channels are blocked with weeds, and amongst them larvae of II. culicifacies and $M$. rossii were found in abundance.

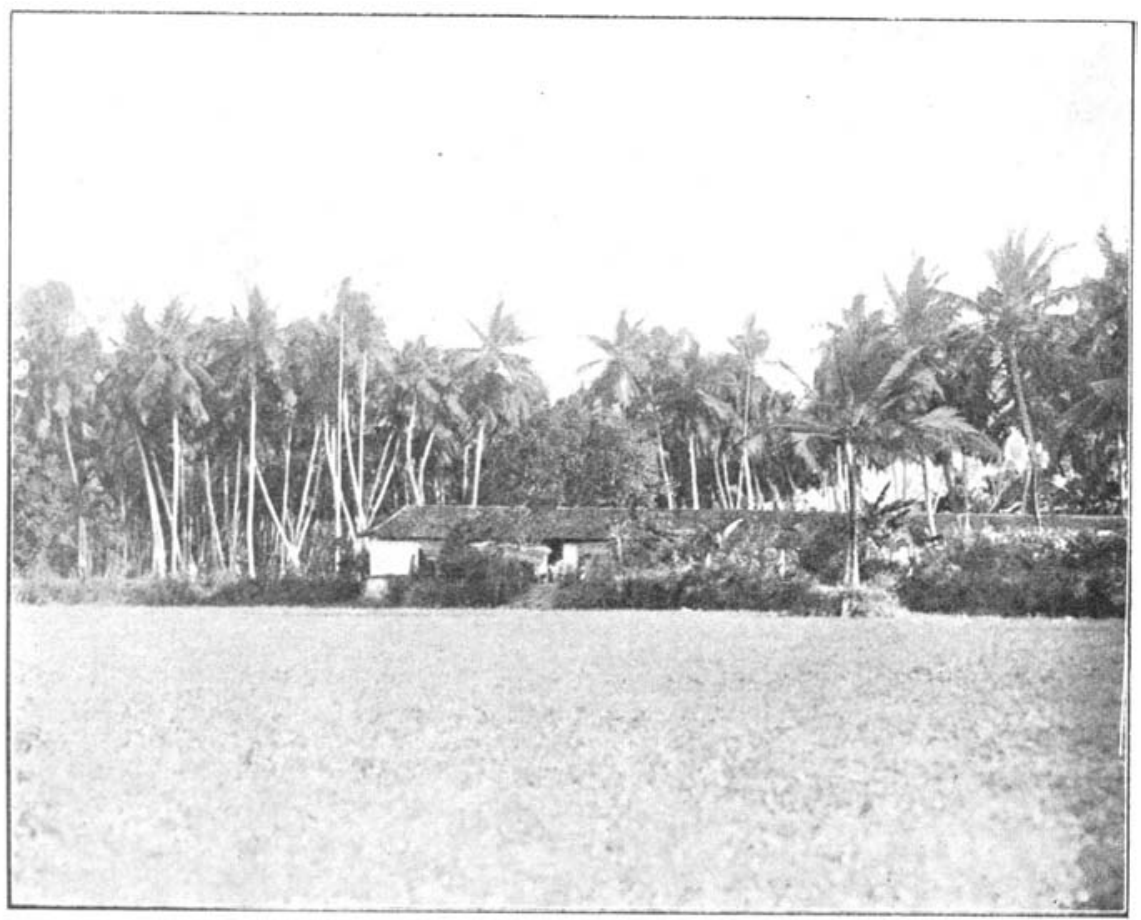

Fig. 9. A block of houses on the Negombo Road built on the Bund of a paddy field. Inhabitants a good class. Spleen rate $68 \cdot 1$ per cent. 
A.-Habage Village.-Inhabitants: class (3), "goiyas." Houses scattered, mud and wattle walls, thatched roofs ; each house in its own compound. No sanitary arrangements. Houses more or less of same type. Nearest house less than quarter of a mile from nearest paddy field. A block of paddy fields on each side of the village.

96 children examined-55 males and 41 females.

Spleen rate 48.9 per cent. ; parasite rate 10.4 per cent.

Eleven children treated regularly with quinine.

B.-A block of brick and mortar cottages inhabited by class (2), "boutiquekeepers," situated on Colombo road. Sanitary arrangements better than in most places, one or two latrines being provided. The nearest house is situated only 10 yards from paddy fields.

19 children examined -7 males and 12 fenales.

Spleen rate $26 \cdot 3$ per cent. ; parasite rate $15 \cdot 7$ per cent.

Three children treated regularly with quinine.

C.-A row of well-built wooden houses, mostly shops and boutiques, inhabited by class (1), on Colombo road. Children, mostly police sergeants' and constables', well fed and of a good class. Latrines provided. Nearest house situated quarter of a mile from paddy fields.

10 children examined -4 males and 6 females.

Spleen rate 0 per cent.; parasite rate 0 per cent.

One child treated regularly with quinine.

D.-Row of semi-detached houses on Rajaphilla road inhabited by class (1), police sergeants. Only two years resident in Kurunegala. Children well-fed and well cared for. Houses clean, whitewashed yearly. Latrines provided. Nearest house 20 yards from paddy fields.

19 children examined -5 males and 13 females.

Spleen rate $26 \cdot 3$ per cent. ; parasite rate $15 \cdot 5$ per cent.

Three children treated regularly with quinine.

E.-A collection of scattered huts situated near Kandy road inhabited by class (3), "goiyas." Poor houses. Cadjan roof and walls. Each house situated in its own compound. No latrines. Children poorly fed: nearest house situated 10 yards from paddy fields, and from an irrigation channel fed by Wenaruwewa tank one mile outside town limits.

24 children examined -17 males and 7 females.

Spleen rate $66 \cdot 6$ per cent. ; parasite rate $4 \cdot 1$ per cent.

Five children treated regularly with quinine.

F.-Quarters of the Tamil oilmongers, class (4), situated on Puttalam road. A bathing tank on one side below Angangalla rock; a tall row of cocoanut and arecanut palms on the other. Deep tank, one acre in extent, full of fish. No anopheline larvae found. Houses of a very poor description huddled together, built for the most part of mud and wattle with cadjan roofs. Inbabitants overcrowded. No latrines. Back premises where oil mills are situated in a most insanitary condition. Nearest house situated 150 yards from paddy fields, but screened by belt of trees already mentioned. 
67 children examined-44 males and 23 females.

Spleen rate 35.8 per cent. ; parasite rate 10.4 per cent.

Seven children treated regularly with quinine.

G.-Gangoda Village.-A Sinhalese settlement of better class "goiyas" class (3). There is one modern brick house with tiled roof; the rest are of mud and wattle with cadjan roofs. Each house situated in its own compound. No latrines. Nearest house situated within 20 yards of paddy fields containing anopheline larvae. Separated from $\mathrm{F}$ by a row of palms.

12 children examined.

Spleen rate 83.3 per cent. ; parasite rate 25 per cent.

One child only treated regularly with quinine.

H.-A row of closely adjoining overcrowded houses on the Negombo road inhabited by class (3), "goiyas." Each house with a small compound at the back and provided with a latrine. Houses built of brick and mortar with tiled roof. A number of inhabitants are employed in the cocoanut mills. Children are better fed and cared for than are the majority of the village children. The foundations of the houses are situated on the actual Bund of the paddy fields, as is shown in Pl. XII, fig. 9.

22 children examined-13 males and 9 females.

Spleen rate $68 \cdot 1$ per cent. ; parasite rate 4.5 per cent.

Four children treated regularly with quinine.

J.-A congregation of houses scattered over an area of about half a mile in extent amongst cocoanut land and inhabited by class (3), "goiyas," bordered by a block of paddy fields on one side and bare rock on the other. Houses poor; cadjan roof and walls. No latrines. Irrigation channel. A branch of main channel fed from Kurunegala tank runs through the centre of the village. The gradient of this channel is so construcled that the water wells up and leaves pools of stagnant water behind, in which anopheline larvae are found.

25 children examined-14 males and 11 females.

Spleen rate 36 per cent. ; parasite rate 12 per cent.

Four children treated regularly with quinine.

K.-Madagama Village.-A collection of cadjan houses situated amongst cocoanuts and inhabited by class (3), "goiyas." Ample space between each house surrounded by compound. Small paddy block of one acre in extent within 20 yards of a group of houses. This block is not irrigated, but is filled with rain water, and is cultivated once a year. On the town side there is a large block of paddy fields within 150 yards of the nearest house.

39 children examined- 17 males and 22 females.

Spleen rate $35 \cdot 8$ per cent. ; parasite rate $12 \cdot 8$ per cent.

No children treated regularly with quinine.

L.-The Bazaar, in Kurunegala town itself. Boutiques on each side of the main streets of the town inhabited by class (2), "boutique-keepers and artisans" of all nationalities-Sinhalese, Tamils, Moors, and Malays. Houses : some built of brick, others mud and wattle with tiled roofs. Curry stuffs, dried fish, and sundry articles for sale; grossly overcrowded. Great numbers of children. Some houses have 


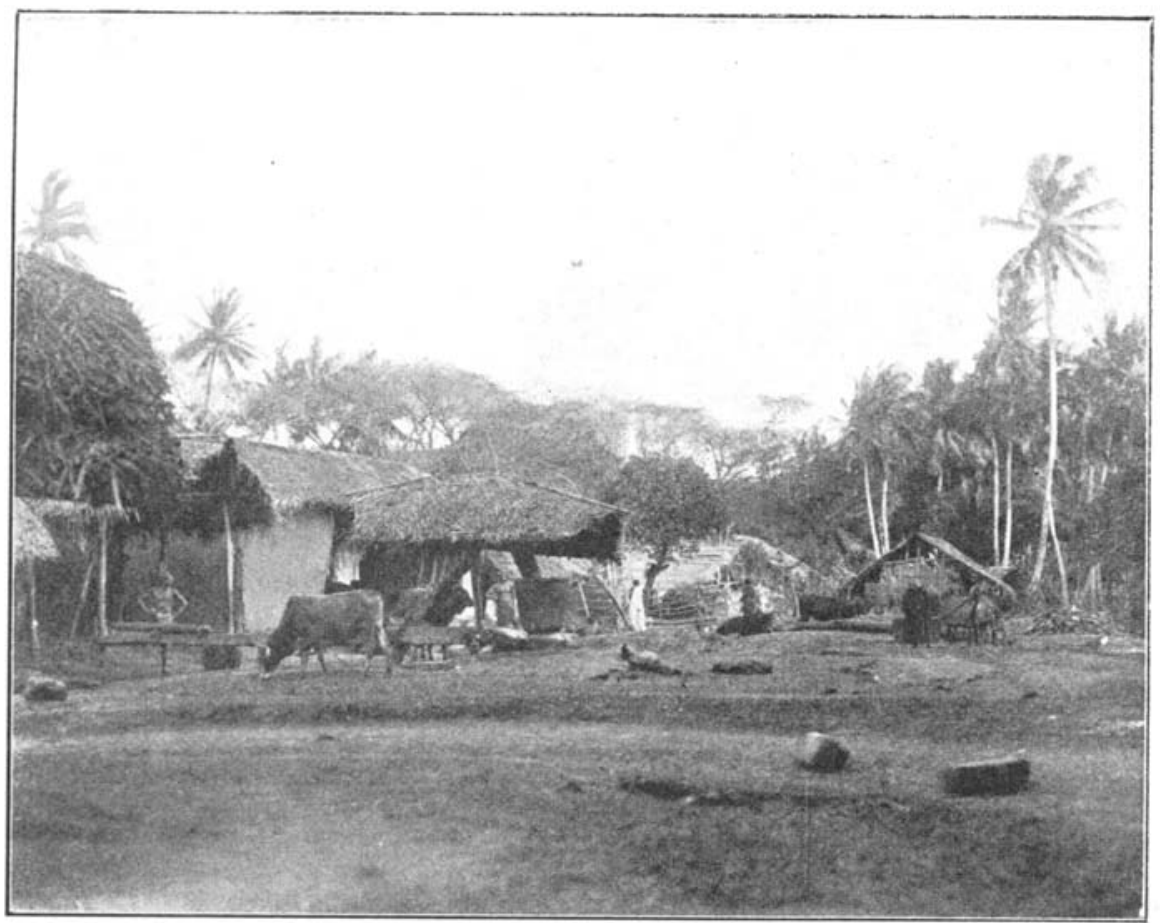

Fig. 10. Oil-Mill Yards. Ill-kempt and insanitary quarters of the Tamils. The spleen rate here is less than half of that in Gangoda, a Sinhalese village within 200 yards, but separated by the belt of cocoanut and areca palms seen on the right of the picture.

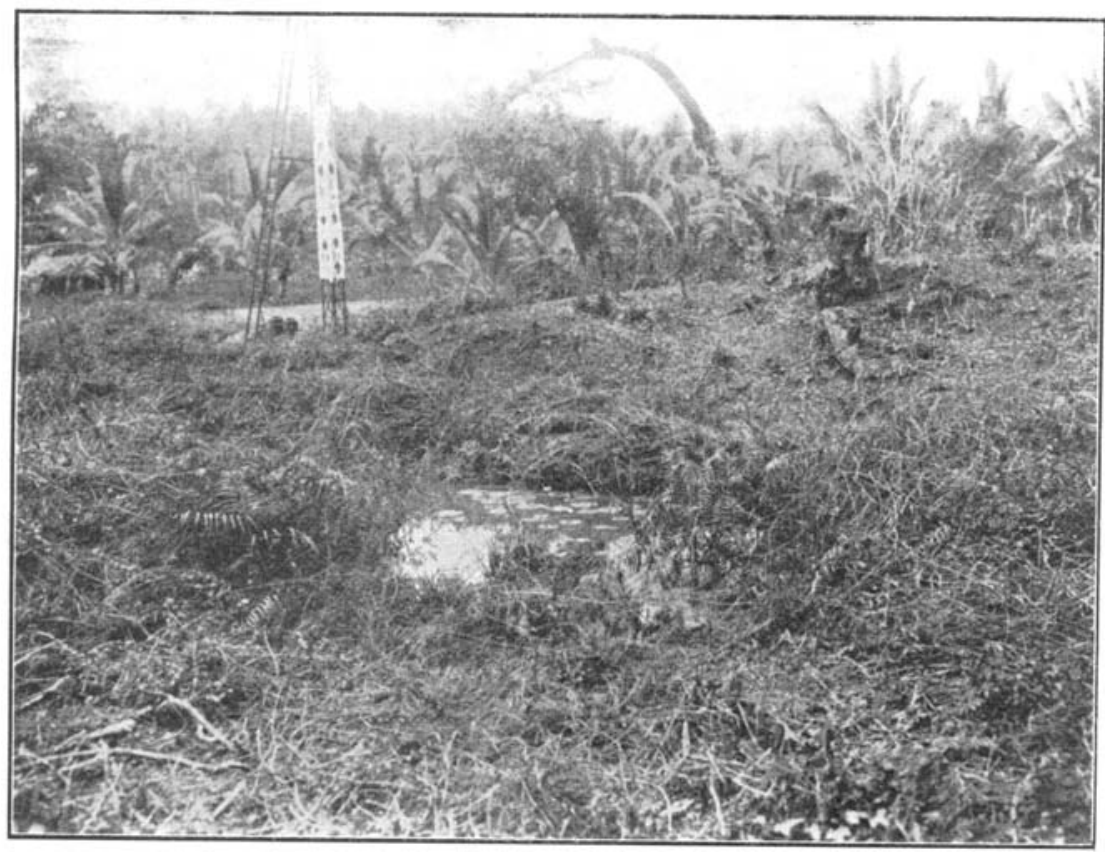

Fig. 11. A borrow Pit. One of the sins of the Public Works Department and a breeding ground of anophelines. Most of these pits have now been filled in. 
private latrines. The only standing water in immediate vicinity is a rock pool, quarter of an acre in extent, in the quarry.

102 children examined-55 males and 47 females.

Spleen rate $7 \cdot 8$ per cent.; parasite rate $8 \cdot 9$ per cent.

Five children regularly treated with quinine.

\section{APPENDIX III.}

\section{Details of Malaria Parasites found.}

Malaria parasites were found 45 times in 435 blood specimens.

The quartan parasite greatly predominated.

Quartan found 33 times, tertian found 12 times.

Sub-tertian crescents found three times.

There were two double infections : one a tertian and quartan, the other tertian and sub-tertian crescents.

One of the 33 times in which the quartan parasite was found, it existed as the gametocyte stage and the infection was an extremely scanty one in all cases except two. In five instances only one gametocyte cell could be found in the film. In five out of the 11 cases in which the tertian parasite was found, the gametocyte stage was also represented; in three instances also one gametocyte cell only could be found in the film. The sub-tertian parasite was found solely in the crescent stage.

\section{ApPEndix IV \\ Statistics showing the effects of systematic treatment with Quinine Pills.}

Of 43 children treated regularly with quinine, 60.4 per cent. had enlarged spleens, 13.9 per cent. had parasites in their blood.

$392 \mathrm{had}$ had no regular treatment with quinine, 33.8 per cent. had parasites in their blood.

\section{Appendix V.}

\section{Figures bearing on the Drainage of the Paddy Fields in Kurunegala.}

I am indebted to Mr E. B. Daniels, a recognized authority on paddy land cultivation in Kurunegala, for figures regarding the relative values of paddy and cocoanut lands in Kurunegala.

1. Valuation of Paddy Land.-Paddy land in the centre of the town is appraised at Rs. 200 an acre, though the owners' valuation is in some instances lower than this -Rs. 150 an acre. The average value of the best paddy land is about Rs. 250 an acre.

Many of the paddy fields in the town are cultivated but once a year, as the soil has lost its fertilizing power through too intense cultivation. 
The crops are easily affected by drought. The yield of paddy from the fields in Kurunegala town is rapidly decreasing. Thus, the return from one block which a few years ago was 40 amunams an acre now averages but 8 amunams for the last two crops, in spite of an ample rainfall. The actual return from paddy land to the owner is, however, far less than this.

It is the custom for the owner to present the seed paddy to the "goiyas" (cultivators), and they in return for cultivating the fields retain balf the crop for their own use.

On this basis, average paddy land brings in a return of about Rs. 50 per acre per annum to the owner, as follows :

2 bushels paddy $=1$ bushel of rice.

8 amunams paddy ( 40 bushels) $=20$ bushels of rice.

20 bushels of rice at Rs. $5^{1}$ a bushel=Rs. 100 .

Rs. 50 to the "goiya" and Rs. 50 to the owner per annum.

2. Valuation of Cocoanut land in. Kurunegala.-Cocoanut land in the town is appraised at Rs. 1000 per acre for bearing land. An estimation of Rs. 10 is made for every tree in bearing.

Kurunegala district is a well-known district for cocoanuts. Most of the cocoanut land in the vicinity of the town is old paddy land. Cocoanuts in Kurunegala take on an average between ten to twelve years to come into bearing. The price of cocoanuts has in recent years substantially risen in Kurunegala.

Ten to 35 years ago cocoanuts sold at the highest at Rs. 40 per thousand; for the last six years the price has stood at Rs. 70 per thousand, and is now steadily increasing.

Copra, locally made, is selling at Rs. 80 a candy, the highest price ever reached.

In a fully-bearing cocoanut plantation there are six pickings per annum (every two months). The average number of trees per acre is 60 , and the yield per tree averages 60 nuts per annum $=3600$ nuts per acre per annum; this, at an average price of Rs. 50 per thousand, gives a return of Rs. 180 per acre per annum.

3. Valuation of Paddy Lands as Building Lots.-As building lots old paddy lands would bring in a large return. There is at present a great scarcity of housing accommodation in Kurunegala. The Salaries Commission has already drawn attention to this fact. Rents are very high. Latterly, on the outskirts of the town, building lots have been selling at Rs. 2000 per acre. There is reason to believe that building lots within town limits would yield double that figure.

4. Catch Crops.-During the period (12 years) in which the cocoanut trees are coming into bearing it is suggested that certain catch crops could be grown. The following are suggested:

Cassava or Manioc, a surface feeder, which does not interfere with the growth of the young cocoanuts, and does not impoverish the soil.

Sweet potatoes, a crop which materially aids the cocoanut palm, as its cultivation entails the turning of the soil every six months.

Plantains do well, but do not pay.

Kitchen vegetables: chillies, pumpkins, egg plants, etc. For all these products there is a local market.

1 The value of a Rupee is equal to $18.4 d$. 
5. General Considerations.-From a perusal of the figures given above, it will be seen that the conversion of paddy into cocoanut land in Kurunegala is a commercially sound venture.

The paddy blocks are naturally a marshy soil, and must therefore be surface drained for cocoanut land. I understand that the general configuration of the town presents no insuperable obstacles to efficient drainage.

It only remains to consider how those interested in paddy field cultivation should be compensated. The general local feeling appears to be that immediately wet cultivation within town limits is prohibited, owners will not sell their lands, so that there will be no need for Government to acquire these lands.

As regards the "goiyas," who for generations have been engaged in paddy field eultivation, they will no doubt require some sort of compensation for loss of their occupation. It may be found practicable to allow them to acquire land elsewhere, or to employ them in making and repairing the necessary surface drains.

The malaria statistics obtained in Kurunegala should be compared with similar figures collected in the Southern Province.

The Tangalla district on the south coast is a hot damp low-lying area, the villagers are poor and ill-nourished; their huts are of the meanest description constructed of "cadjan," a sort of cocoanut matting. The inhabitants cultivate small plots of millet and citronella grass; in the vicinity of some of the villages investigated there are large natural swamps and a few irrigated paddy fields.

The adults, but more especially the children, have an unhealthy appearance, they are obviously anaemic, their skins are rough and their bellies protuberant.

Time did not permit me to make a collection of the local anophelines, but from an examination of 65 Sinhalese villagers of all ages I was able to obtain some idea of the intensity of the malaria.

The spleen rate was $86.1 \%$ and the parasite rate $29 \cdot 2 \%$. The quartan parasite was found eleven times, the tertian parasite twice; the subtertian eight times (rings three times, crescents five). Double infections were found twice; once tertian and quartan rings; and once quartan rings and subtertian crescents.

In this intensely malarious area nothing has so far been done in the way of preventive measures; it is feared that the free distribution of quinine by the Government Authorities has had little effect in diminishing the frequency or in preventing fresh infections.

The natives are in the habit of attending the hospitals and dispensaries only when suffering from an attack of fever, but not during the intervals. The compulsory distribution of quinine to gangs of coolies, as for instance in the Public Works Department, is an unpopular 
measure; the men have a great aversion to the taste of the raw drug in liquid form, and it is feared that more often than not the medicine is thrown away.

A few observations were also made in Badulla (2200 ft.) a town of 6400 inhabitants, the capital of the Province of Uva, and the centre of a large tea-bearing district.

There is a heavy rainfall of 75 ins. per annum and the average temperature is $73^{\circ} \mathrm{F}$. The town lies in a hollow, shut in on all sides by precipitous hills rising to $4000 \mathrm{ft}$.

As in the case of Kurunegala there is a block of terraced paddy fields about 100 acres in extent constantly irrigated by running water.

Epidemics have occurred in the town in recent years, and apparently a considerable number of fresh infections occur in the wards of the Government hospital which abuts the block of paddy fields already mentioned, even though the whole building has been lately efficiently screened with wire gauze.

In the few fever cases I was able to investigate the quartan parasite alone was found.

In the paddy fields adjoining the hospital large numbers of anopheline larvae were secured. $M$. barbirostris and sinensis, Myzomyia rossii and culicifacies, and $M$. punctulata were found to be the most abundant species.

Dr Van Rooyen, the resident medical officer, has in the last two years, been in the habit of treating the paddy fields in the vicinity of the hospital once every week with a strong solution of cresoline; there is no doubt that this substance is an efficient larvicide and is harmless to the sprouting rice-plants, but its effects can only be of the most transient character as it is almost immediately swept away by the water overflowing from the terraces above on to those below.

It is possible that with modifications suited to local conditions the recommendations I put forward in Kurunegala apply to Badulla also. It is essential that the offending block of paddy fields in the centre of the town should be abolished and dry cultivation substituted. 